\title{
Prone positioning in acute respiratory distress syndrome during venovenous extracorporeal membrane oxygenation
}

Shiping Zhu ${ }^{1 *}$ (1)

Keywords: ARDS, Prone positioning, Mortality, Meta-analysis

\section{Dear Editor,}

We read with respect the recent study by Dr. Poon [1], which investigated the potential benefit of prone positioning (PP) during venovenous extracorporeal membrane oxygenation (ECMO) in patients with acute respiratory distress syndrome (ARDS). Total of 11 studies were included and the pooled result showed a non-significant increasing trend of survival rate in patients receiving PP during ECMO (RR 1.2, 95\% CI 0.9-1.5). We would like to add some comments.

First, in the forest plot, we noted that the result from Garcia-2020's study was significantly different from others. We performed a sensitivity analysis by excluding Garcia-2020's study (Fig. 1), and the pooled result became statistically significant (RR 1.28, 95\% CI 1.08-1.52). We believe several reasons may help to explain this finding. $1>$ In Garcia-2020's study, the overall mortality rate was significantly higher than others ( $85 \%$ vs. $30-60 \%$ ), which suggested potential heterogeneity within these ARDS cohorts. Therefore, whether PP during ECMO presented different efficacy in different ARDS phenotypes needs to be further investigated. $2>\mathrm{PP}$ during ECMO is still not routinely applied to patients during ECMO, due to risk of life-threatening complications, such as cannula dislodgement. In all these included studies, the indications for PP differed significantly. In Garcia-2020's study, PP was only used in case of severe hypoxemia or extensive lung consolidation, which generated an inter-relationship between PP and disease severity due to selection bias. However, in Giani-2020's and Schmidt's studies, PP is routinely performed or encouraged during ECMO. The indications in Chaplin-2020, Guervilly-2020, Yang-2021 and Rilinge-2020's studies were unclear. Therefore, we suggest that these conditions should be considered when interpreting the pooled result of the current study.

Second, a meta-analysis aims to pool studies with similar design, cohort, intervention, and outcomes. This also one reason for the debate that whether observational studies and randomized controlled studies should be included in one meta-analysis [2, 3]. In the current study, both the unadjusted findings from four studies and results after propensity score matching (PSM) from three studies were included in one forest plot. We suggest that the unadjusted findings and adjusted result (PSM or regression) should be separated [4].

This comment refers to the article available online at https://doi.org/10.1186/ s13054-021-03723-1.

\footnotetext{
*Correspondence: zsping0908@163.com

${ }^{1}$ Department of Respiratory Medicine, Hangzhou Hospital of Traditional Chinese Medicine, No. 453, Tiyuchang Road, Hangzhou 310000, Zhejiang, China
} original author(s) and the source, provide a link to the Creative Commons licence, and indicate if changes were made. The images or other third party material in this article are included in the article's Creative Commons licence, unless indicated otherwise in a credit line to the material. If material is not included in the article's Creative Commons licence and your intended use is not permitted by statutory regulation or exceeds the permitted use, you will need to obtain permission directly from the copyright holder. To view a copy of this licence, visit http://creativecommons.org/licenses/by/4.0/. The Creative Commons Public Domain Dedication waiver (http://creativeco mmons.org/publicdomain/zero/1.0/) applies to the data made available in this article, unless otherwise stated in a credit line to the data. 


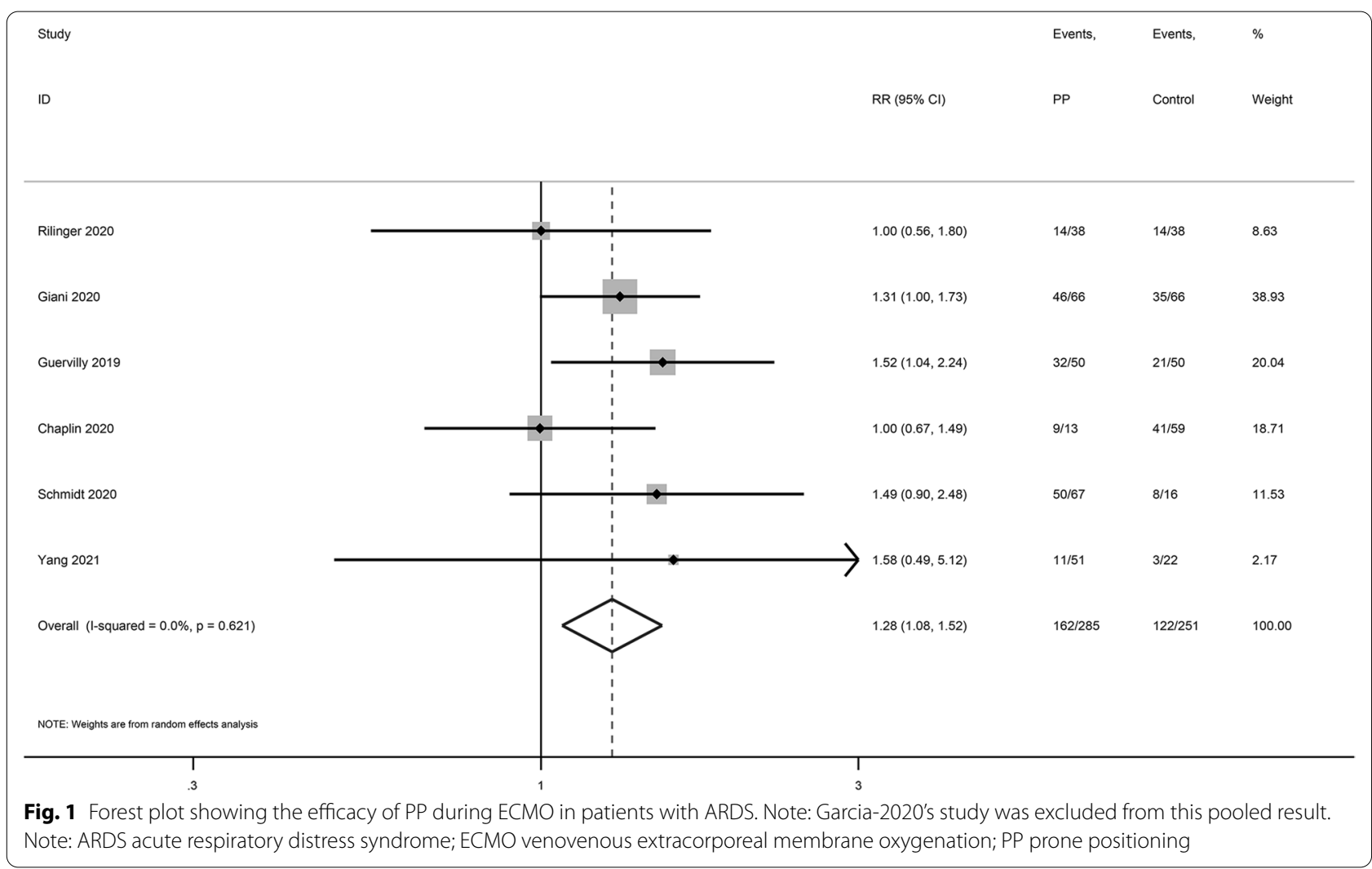

\section{Authors' response \\ Prone Positioning During Venovenous Extracorporeal Membrane Oxygenation for Acute Respiratory Distress Syndrome: Reply}

Wynne Hsing Poon ${ }^{2} \mathbb{D}$, Kollengode Ramanathan ${ }^{2,3,9}$, Ryan Ruiyang Ling ${ }^{2} \mathbb{B}$, Matthieu Schmidt ${ }^{4,5}$ and Kiran Shekar ${ }^{6,7,8,9}$ (1)

${ }^{2}$ Yong Loo Lin School of Medicine, National University of Singapore, Singapore, Singapore.

${ }^{3}$ Cardiothoracic Intensive Care Unit, National University Heart Centre, National University Hospital, Singapore, Singapore.

${ }^{4}$ Service de Médecine Intensive-Réanimation, Institut de Cardiologie, Assistance Publique-Hôpitaux de Paris, Hôpital Pitié-Salpêtrière, Paris, France. ${ }^{5}$ Sorbonne Université, GRC 30, Reanimation Et Soins Intensifs du Patient en Insuffisance Respiratoire aigüE, AP-HP, Hôpital de La Pitié Salpêtrière, 75013 Paris, France.

${ }^{6}$ Adult Intensive Care Services, Prince Charles Hospital, Brisbane, QLD, Australia. ${ }^{7}$ Queensland University of Technology, Brisbane, Australia.

${ }^{8}$ University of Queensland, Brisbane, Australia.

${ }^{9}$ Bond University, Gold Coast, QLD, Australia.

Wynne Hsing Poon and Kollengode Ramanathan have contributed equally to this work

We thank Dr Zhu for the attention and valuable comments provided regarding our article. The indications for prone positioning (PP) during extracorporeal membrane oxygenation (ECMO) were indeed variable across studies, as outlined in our Supplementary Table 2 of our original manuscript [1]. Based on our a priori criteria for sensitivity analyses (Joanna Briggs Institute score $<8$ ), the exclusion of study by Garcia et al., which primarily focused on COVID-19 patients, was not indicated. While we note that the sensitivity analysis suggested found significant survival benefits, this would be an unplanned post-hoc analysis, which should be considered exploratory and interpreted carefully [5].

Despite varied indications for PP, the baseline PF ratio reported by Garcia et al. $(82.3 \pm 22.5)$ was relatively similar to Giani et al. $(73 \pm 29)$ and Schmidt et al. (all patients, 60 [54-68]), suggesting a similar degree of refractory hypoxemia despite ECMO support. Additionally, metaregression analysis found that PF ratio did not independently influence patient survival. Though establishing an inter-relationship between disease severity or ARDS phenotypes and concurrent PP during ECMO goes beyond the scope of our meta-analysis, we wholly agree with Dr. Zhu that further studies should be conducted to shed light on these thought-provoking insights.

A plausible reason for the increased mortality reported by Garcia et al. could be related to the planning and provision of ECMO services during the COVID-19 pandemic [6]. With a pandemic-stricken and overwhelmed healthcare system, it is possible that patient outcomes are affected. Our subgroup analysis, albeit insignificant, also 
Table 1 Subgroup analysis based on study data type for chance of cumulative survival

\begin{tabular}{lllll}
\hline Data type & $\begin{array}{l}\text { No. of } \\
\text { studies }\end{array}$ & $\begin{array}{l}\text { RR }(95 \% \\
\text { confidence } \\
\text { interval) }\end{array}$ & $\boldsymbol{P}$ value & $\begin{array}{l}\boldsymbol{P} \text { value for } \\
\text { interaction }\end{array}$ \\
\hline Non-PSM & 4 & $0.98[0.54-1.79]$ & 0.95 & 0.354 \\
PSM & 3 & $1.33[1.07-1.64]$ & 0.0086 & \\
\hline
\end{tabular}

PSM Propensity score matched

found a trend towards decreased survival in patients with COVID-19 (37\%) compared to those without (64\%).

This meta-analysis of observational studies aimed to summarize all available information on the application of PP with ECMO. The Cochrane recommendations suggest that in a meta-analysis of non-randomized data, adjusted results should be collected where possible [7]. However, we appreciate the suggestion to separate adjusted and unadjusted data, for which an additional analysis found no significant difference between groups (Table 1).

While the adjusted data suggest significant survival benefit, this should be interpreted with caution as the conclusions are based on observational study-level data from three studies. As we understand ARDS and its therapeutic interventions better, the clinical outcomes of patients are likely to improve. Clinical decisions for these patients should evolve with time, while being evidence based. Better evidence should be obtained from wellconducted clinical trials to elucidate whether PP during ECMO demonstrates a survival benefit and identify patients who are most likely to benefit.

\section{Acknowledgements}

Not applicable.

\section{Authors' contributions}

SZ came up with the question and was responsible for writing.

\section{Funding}

None.
Availability of data and materials

Not applicable.

\section{Declarations}

Ethics approval and consent to participate

Not applicable.

\section{Consent for publication}

Not applicable.

\section{Competing interests}

The authors declare that they have no competing interests.

Received: 18 August 2021 Accepted: 20 August 2021

Published online: 18 October 2021

\section{References}

1. Poon WH, Ramanathan K, Ling RR, Yang IX, Tan CS, Schmidt M, Shekar K. Prone positioning during venovenous extracorporeal membrane oxygenation for acute respiratory distress syndrome: a systematic review and meta-analysis. Crit Care. 2021;25(1):292. https://doi.org/10.1186/ s13054-021-03723-1.

2. Shrier I, Boivin JF, Steele RJ, Platt RW, Furlan A, Kakuma R, Brophy J, Rossignol M. Should meta-analyses of interventions include observational studies in addition to randomized controlled trials? A critical examination of underlying principles. Am J Epidemiol. 2007;166(10):1203-9.

3. Kunz R, Khan KS, Neumayer HH. Observational studies and randomized trials. N Engl J Med 2000;343(16):1194-1195; author reply 1196-1197.

4. Peters J, Mengersen K. Selective reporting of adjusted estimates in observational epidemiology studies: reasons and implications for metaanalyses. Eval Health Prof. 2008;31(4):370-89.

5. Curran-Everett D, Milgrom H. Post-hoc data analysis: benefits and limitations. Curr Opin Allergy Clin Immunol. 2013;13(3):223-4.

6. Ramanathan K, Antognini D, Combes A, Paden M, Zakhary B, Ogino M, MacLaren G, Brodie D, Shekar K. Planning and provision of ECMO services for severe ARDS during the COVID-19 pandemic and other outbreaks of emerging infectious diseases. Lancet Respiratory Med. 2020;8(5):518-26.

7. Reeves BCDJ, Higgins JPT, Shea B, Tugwell P, Wells GA. Chapter 24: including non-randomized studies on intervention effects. Cochrane Handbook for Systematic Reviews of Interventions version 6.2 (updated February 2021). Cochrane. In: Higgins JP, Thomas J, Chandler J, Cumpston M, LiT, Page MJ, Welch VA, editors. Cochrane handbook for systematic reviews of interventions. Hoboken: Wiley; 2021.

\section{Publisher's Note}

Springer Nature remains neutral with regard to jurisdictional claims in published maps and institutional affiliations.

Ready to submit your research? Choose BMC and benefit from:

- fast, convenient online submission

- thorough peer review by experienced researchers in your field

- rapid publication on acceptance

- support for research data, including large and complex data types

- gold Open Access which fosters wider collaboration and increased citations

- maximum visibility for your research: over $100 \mathrm{M}$ website views per year

At BMC, research is always in progress.

Learn more biomedcentral.com/submissions 